\title{
Placental thickness as a sonographic biomarker for gestational age among singleton pregnancies
}

\author{
Gokul Reshmi Mariappan ${ }^{1}$, Hiremath B. Panchaksharayya1, Govardhanan R ${ }^{2 *}$
}

\begin{abstract}
${ }^{1}$ Department of Obstetrics and Gynaecology, ${ }^{2}$ Department of Radiology, Sri Venkateswaraa medical college hospital and Research centre, Ariyur, Pondicherry, India
\end{abstract}

Received: 04 September 2020

Accepted: 07 October 2020

\author{
*Correspondence: \\ Dr. Govardhanan R, \\ E-mail:kovhlm@gmail.com
}

Copyright: (c) the author(s), publisher and licensee Medip Academy. This is an open-access article distributed under the terms of the Creative Commons Attribution Non-Commercial License, which permits unrestricted non-commercial use, distribution, and reproduction in any medium, provided the original work is properly cited.

\begin{abstract}
Background: The aim of the study was to exploring the application of placental thickness as a sonographic marker for determining gestational age among singleton pregnant mothers.

Methods: This longitudinal, observational study was conducted in obstetrics and gynecology department and department of Radiology, Sri Venkateshwaraa Medical College and Hospital, Ariyur, Puducherry, in antenatal mothers of 11-40 weeks of gestation from 2018 to 2019. The study included 278 normal singleton pregnant women. The details regarding the socio-demographic variables, relevant clinical history and examination, laboratory investigations and ultrasound report containing gestational age, placental thickness measured at the level of cord insertion were documented in a proforma. The sonographic measurements were made using a grey scale real time ultrasound machine Siemens ACUSON x400 with a convex 2-5 mhz probe.

Results: The study included 278 pregnant women with a mean age of $25.8 \pm 44$ years. Majority of them were home makers $(\mathrm{n}=155,55.7 \%)$ and educated $(\mathrm{n}=257,92.4 \%)$ and primigravida

$(\mathrm{n}=117,57.9 \%)$. The position of the placenta in majority of the participants was posterior placed $(71.6 \%)$. The mean gestational age of the studied antenatal women was $28.3 \pm 7.2$ weeks as per ultrasonogram. Majority of the participants were younger aged between 20 to 30 years of age and very few teenage pregnancies. There was a significant correlation between the gestational age and placental thickness $(\mathrm{p}<0.001)$. There was a significant $(\mathrm{p}<0.001)$ correlation between placental thickness and femur length $(r=0.972)$.

Conclusions: The placental thickness showed significant positive correlation with the gestational age as measured by ultrasonogram. Hence it can be used as a parameter in determining the gestational age.
\end{abstract}

Keywords: Gestational age, Placental thickness, Sonographic marker

\section{INTRODUCTION}

Gestational age estimation plays a trivial role in evaluation of fetal growth, risk assessment of fetal anomalies, interpreting various parameters related to gestation and aids the obstetrician in undertaking appropriate interventions to minimize pregnancy complications. ${ }^{1}$ Placental size or thickness serves as an important predictor of fetal growth and it has been shown to vary in concordance with varied perinatal outcomes. Previous studies have documented that small placentas are associated with chromosomal abnormalities, preeclampsia, maternal diabetes mellitus, infections and intrauterine growth restriction and thicker placentas at term were associated with hydrops fetalis, diabetes mellitus and perinatal infections. ${ }^{2}$ Placental thickness is an easy to measure parameter and has shown consistent variation with the gestational age. ${ }^{3}$ This study aims at 
exploring the application of placental thickness as a sonographic marker for gestational age among a group of singleton pregnant mothers attending to the tertiary care hospital.

\section{METHODS}

This longitudinal, observational study was conducted among the antenatal mothers attending to the obstetrics and Gynaecology outpatient department, Sri Venkateshwaraa Medical College and Hospital, Ariyur, Puducherry, for regular antenatal visits from 11-40 weeks of gestation. An Institutional Ethics committee approval was obtained prior to the start of the study. The study included 278 normal singleton pregnant women as subjects who attended to the obstetrics out patient department from 2018 to 2019.

The study excluded those mothers with gestational hypertension, foetal anomalies, multiple gestation, placenta previa, anaemia, unknown last menstrual cycle and other placental anomalies causing poor visualisation of the placenta and intrauterine growth restriction. The antenatal women included in the study were explained regarding the non-invasive and harmless nature of the study in their own comprehensible language and written consent was obtained.

The details regarding the socio-demographic variables, relevant clinical history and examination, laboratory investigations and ultrasound report containing gestational age, placental thickness measured at the level of cord insertion were documented in a proforma.

\section{Sonographic equipment's and measurement technique}

The sonographic measurements were made using a grey scale real time ultrasound machine Siemens ACUSON x400 with a convex 2-5 MHz probe. In supine position, foetus was examined for viability and anomalies and Amniotic Fluid Index.
The foetuses were observed for gestational age estimation using Femur length in the second trimester. From various combinations of measurements, based on Hadlock tables and using regression equations, the composite average of the gestational age was estimated for each foetus by taking various growth parameters by the ultrasound machine The following sonographic fetal parameter measurements were made to estimate the gestational age which included Biparietal Diameter (BPD), Head Circumference (HC), Abdominal Circumference (AC), and Femur Length (FL).

Estimated gestational age was computed by the ultrasound machine based on the Hadlock tables by the inbuilt computation software. Placental thickness was measured at the level of cord insertion by drawing a straight line up to the maternal surface of the placenta and the maximum thickness was noted in the cross section. Reconfirmation of the site of insertion was done using Umbilical artery Colour Doppler. Each placenta was measured to a $1 \mathrm{~mm}$ precision, at its greatest thickness, which was perpendicular to the uterine wall.

\section{Statistical Analysis}

Data was entered into Microsoft excel worksheet and analysed using SPSS version 20.0. The gestational age, placental thickness and other continuous variables are represented as means and standard deviation within $95 \%$ confidence intervals. Pearson correlation test was used to find the correlation between placental thickness and gestational age. A p-value of less than 0.05 is considered statistically significant.

\section{RESULTS}

The study included 278 pregnant women with a mean age of $25.8 \pm 44$ years. Majority of them were home makers $(\mathrm{n}=155,55.7 \%)$ and educated $(\mathrm{n}=257,92.4 \%)$ and primigravida $(\mathrm{n}=117,57.9 \%)$.

Table 1: Age distribution associated with placental location and GA (in weeks).

\begin{tabular}{|llllll|}
\hline Age (in years) & $\mathbf{N}(\%)$ & Mean gestational age (in weeks) & \multicolumn{2}{l|}{ Placental position } & Posterior \\
\hline$\leq \mathbf{2 0}$ & $35(12.6)$ & $29.1 \pm 5.2$ & $22(62.9)$ & $9(25.7)$ & $4(11.4)$ \\
\hline $\mathbf{2 1 - 2 5}$ & $111(39.9)$ & $28.7 \pm 4.3$ & $80(72.1)$ & $18(16.2)$ & $13(11.7)$ \\
\hline $\mathbf{2 6 - 3 0}$ & $103(37.1)$ & $27.6 \pm 8.6$ & $77(74.8)$ & $19(18.4)$ & $7(6.8)$ \\
\hline $\mathbf{3 1 - 3 5}$ & $19(6.8)$ & $28.1 \pm 2.2$ & $11(57.9)$ & $3(15.8)$ & $5(26.3)$ \\
\hline$>\mathbf{3 5}$ & $10(3.6)$ & $29.4 \pm 9.3$ & $9(90)$ & $0(0)$ & $1(10)$ \\
\hline Total & $278(100)$ & $28.3 \pm 7.2$ & $199(71.6)$ & $49(17.6)$ & $30(10.8)$ \\
\hline
\end{tabular}

The age distribution, position of the placenta and gestational age of the study participants is given in table 1. The position of the placenta in majority of the participants was posterior placed $(71.6 \%)$. The mean gestational age of the studied antenatal women was $28.3 \pm 7.2$ weeks as per ultra sonogram. Majority of the participants were younger aged between 20 to 30 years of age and very few teenage pregnancies. 
Table 2: Correlation between Gestational age, femur length and Placental thickness.

\begin{tabular}{|llll|}
\hline $\begin{array}{l}\text { Gestational } \\
\text { age (in } \\
\text { weeks) }\end{array}$ & $\mathbf{N}(\%)$ & $\begin{array}{l}\text { Femur } \\
\text { length }\end{array}$ & $\begin{array}{l}\text { Placenta } \\
\text { thickness }\end{array}$ \\
\hline $\mathbf{1 1 - 1 5}$ & $14(5)$ & $34 \pm 0.9$ & $16.52 \pm 6.2$ \\
\hline $\mathbf{1 6 - 2 0}$ & $33(11.9)$ & $9 \pm 1.0$ & $21.8 \pm 5.7$ \\
\hline $\mathbf{2 1 - 2 5}$ & $51(18.3)$ & $0 \pm 1.3$ & $23.6 \pm 6.2$ \\
\hline $\mathbf{2 6 - 3 0}$ & $51(18.3$ & $5 \pm 1.7$ & $29.1 \pm 6.5$ \\
\hline $\mathbf{3 1 - 3 5}$ & $75(27)$ & $5 \pm 2.1$ & $33.3 \pm 5.8$ \\
\hline $\mathbf{3 6 - 3 9}$ & $54(19.4)$ & $3 \pm 2.5$ & $35.6 \pm 4.5$ \\
\hline
\end{tabular}

Pearson Correlation test: (between Gestational age and placental thickness) $r=0.978, \mathrm{p}<0.001$

\section{DISCUSSION}

Placenta is usually visualized as a focal thickening due to chorio-decidual reaction at 8 weeks of gestation. The identification of the placental-myometrial interface is a key to correct measurement of placental thickness. ${ }^{4}$ In the present study antenatal women of gestational age 11 weeks and above were included. Majority of them $(71.6 \%)$ were detected to have a posteriorly placed placenta and it did not show difference based on the age of the mother. In the study by Suresh et al the posterior location $(60.9 \%)$ of the placenta was most common in $<20$ years age group, followed by fundal $(50 \%)$ and lateral $(50 \%)$ in $>30$ years age group, and anterior $(45.6 \%)$ in $21-25$ years age groups. ${ }^{5}$ The study also delineated the linear relationship between the placental thickness and gestational age. It was observed that there was a significant correlation $(r=0.978)$ between the gestational age and placental thickness $(\mathrm{p}<0.001)$.

The study group was divided into six groups based on the gestational age and the placental thickness was studied in each group. It was observed that the mean placental thickness (and SD) varied in such a way that the placental thickness corresponds to the mid points of gestational age except in the earlier gestational weeks (less than 20 weeks) where the placental thickness was beyond the upper limit of gestational age. In the study done by Pant et al the mean placental thickness for groups with gestational age in weeks 14-20, 21-25, 26-30, 31-35 were $18.35,23.62,28.88$ and $32.62 \mathrm{~mm}$ respectively which almost correspond to the mid-points of the gestational age. $^{6}$

Jain et al in their study observed that the mean placental thickness increased with advancing gestational age, almost matching from 27-33 weeks of gestation. ${ }^{7}$ In the present study, there was progressive increment in placental thickness till term in par with the gestational age. In the earlier study by Pant et al the placental thickness almost increased parallel with the placental thickness till 35 weeks of gestation after which it falls by $1-3 \mathrm{~mm}$ than the gestational age. ${ }^{6}$ In the study by Grannum et al there was a gradual decrease in the placental thickness after 32 weeks of gestation till term. ${ }^{8}$

\section{Limitations}

The study include a single time cross-sectional measurement of placental thickness in the ante-natal women hence the difficulty in commenting about growth pattern of placenta as gestational age advances which can be monitored only by serial measurements.

\section{CONCLUSION}

The placental thickness showed significant positive correlation with the gestational age as measured by ultrasonogram. Hence it can be used as a parameter in determining the gestational age. Further studies are needed to determine the variations in growth pattern of the placenta in individual follow-up and in case of anomaly

\section{ACKNOWLEDGMENTS}

Authors would like to thank the management of the tertiary Health Care centre for providing the necessary infrastructure, the patients who consented to participate in the study and the students who helped in conducting the study.

Funding: No funding sources Conflict of interest: None declared

Ethical approval: The study was approved by the Institutional Ethics Committee

\section{REFERENCES}

1. Norton ME, Scoutt L, Feldstein VA. Ultrasonography in Obstetrics and Gynaecology. 5th edition. Callen PW, editor. Philadelphia, PA: Elsevier. 2002;225-65.

2. Habib FA. Prediction of low birth weight infants from ultrasound measurement of placental diameter and thickness. Ann Saudi Med. 2002;22(5-6):312-14.

3. Karthikeyan T, Subramaniam RK, Johnson WMS. Placental Thickness and its correlation to gestational age and Foetal growth parameters. J Clin Diagn Res. 2012;6(10):1732-5.

4. Filly R, Hoddick WK, Mahony BS, Callen PW, Filly $\mathrm{RA}$, et al. Placental thickness. J Ultrasound Med. 1985;4(9):479-82.

5. Suresh KK, Ajey R, Bhagwat SK. Ultrasonographic measurement of placental thickness and its correlation with Femur Length. Int $\mathrm{J}$ Anatomy Radiol Surg. 2009;6(1):46-51.

6. Pant S, Dashottar S. A correlative study to evaluate the gestational age by sonological measurement of placental thickness in normal second and third trimester pregnancy. Int J Adv Med. 2017;4:1638-44.

7. Jain A, Kumar G, Agarwal U, Kharakwal S. Placental thickness a sonographic indicator of gestational age. J Obstet Gynaecol Ind. 2001;51(3):48-9. 
8. Grannum PA, Berkowitz RL, Hobbins JC. The ultrasonic changes in the maturing placenta and their relation to fetal pulmonic maturity. American $\mathbf{J}$ Obstetr Gynecol. 1979;133(8):915-22.
Cite this article as: Mariappan GR,

Panchaksharayya HB, Govardhanan R. Placental

thickness as a sonographic biomarker for gestational age among singleton pregnancies. Int J Reprod Contracept Obstet Gynecol 2020;9:4617-20. 